\title{
Pengaruh penambahan bioetanol dari mahkota nanas terhadap emisi gas buang pada mesin motor 4 langkah
}

\author{
Selvia Aprilyanti ${ }^{*}$, Madagaskar ${ }^{2}$, Faizah Suryani ${ }^{3}$ \\ ${ }^{1,3}$ Prodi Teknik Industri, Fakultas Teknik, Universitas Tridinanti Palembang \\ JI. Kapten Marzuki No.2446, Palembang, Indonesia \\ ${ }^{2}$ Prodi Teknik Mesin,Fakultas Teknik, Universitas Tridinanti Palembang \\ Jl. Kapten Marzuki No.2446, Palembang, Indonesia \\ ${ }^{\star}$ Corresponding author: selvia1704@univ-tridinanti.ac.id
}

\begin{abstract}
Bioethanol is ethanol derived from plants that contain cellulose such as cassava, corn and sugar cane. The use of bioethanol aims to overcome the scarcity of fuel and reduce the use of fossil oil ingredients in Indonesia. The introduction of alternative energy is optimized by mixing fossil fuels with bioethanol. Therefore, the use of bioethanol as a renewable fuel is very good if because pure bioethanol has a high octane value of 118. Besides, bioethanol is also able to reduce the amount of carbon monoxide $(\mathrm{CO})$ emissions, decrease Nitrogen Oxide (NOx) and hydrocarbon emissions compared to ordinary gasoline fuel. In this research, a mixture of Pertamax and Bioethanol with a mixture of variations, among others: pure Pertamax (E0), Pertamax mixture and bioethanol 5\% (E5), bioethanol 10\% (E10), and bioethanol $15 \%$ (E15). The fuel testing was carried out at the Environmental Service Laboratory using a 4-stroke Yamaha motorcycle brand. Mixing bioethanol as a fuel can reduce exhaust emissions from the combustion of motorcycle fuel 4 steps in all tests. The best test results obtained on the composition of the E10 fuel mixture with CO levels of $2.06 \%$, CO2 levels of $6.96 \%$ and $\mathrm{HC}$ of $75 \mathrm{ppm}$.
\end{abstract}

Keywords : Bioethanol, Gas Emissions, Hydrocarbons, Carbon Monoxide, Pertamax

\begin{abstract}
Abstrak
Bioetanol merupakan etanol yang berasal dari tumbuh-tumbuhan yang mengandung selulosa seperti singkong, jagung dan tebu. Penggunaan bioetanol bertujuan untuk mengatasi kelangkaan bahan bakar dan mengurangi penggunaan bahan bahan fosil minyak di Indonesia. Pengenalan energi alternatif ini dioptimalkan dengan cara melakukan pencampuran antara bahan bakar fosil dengan bioethanol. Oleh sebab itu, pemanfaatan bioetanol sebagai bahan bakar terbarukan sangat baik jika karena bioetanol murni memiliki nilai oktan yang tinggi sebesar 118. Selain itu, bioetanol juga mampu mengurangi jumlah emisi karbon monoksida (CO), penurunan emisi Nitrogen Oksida (NOx) serta hidrokarbon dibandingkan dengan bahan bakar bensin biasa. Pada penelitian ini dilakukan pencampuran antara bahan bakar pertamax dan bioethanol dengan variasi campuran antara lain : pertamax murni (E0), campuran pertamax dan bioethanol 5\% (E5), bioetanol 10\% (E10), dan bioetanol 15\% (E15). Pengujian bahan bakar tersebut dilakukan di Laboratorium Dinas lingkungan hidup menggunakan sepeda motor 4 langkah merk yamaha fino. Pencampuran bioetanol sebagai bahan bakar mampu mengurangi emisi gas buang dari pembakaran bahan bakar sepeda motor 4 langkah pada semua pengujian. Hasil pengujian yang terbaik diperoleh pada komposisi campuran bahan bakar E10 dengan kadar $\mathrm{CO}$ sebesar 2,06\%, kadar $\mathrm{CO}_{2}$ sebesar 6,96\% dan HC sebesar 75 ppm.
\end{abstract}

Kata kunci : Bioetanol, Emisi Gas, Hidrokarbon, Karbonmonoksida, Pertamax 


\section{Pendahuluan}

Energi kimia yang dihasilkan oleh pembakaran bahan bakar akan mengakibatkan kenaikan suhu dan tekanan dalam silinder dan menggerakkan piston sehingga terjadilah gerak rotasi poros engkol sebagai keluaran mekanis dari motor [1].

Untuk menggerakkan mesin dibutuhkan adanya bahan bakar agar mampu menghasilkan tenaga dari proses pembakaran. Bahan bakar sudah menjadi kebutuhan sehari-hari masyarakat sehingga mengakibatkan kelangkaan dari bahan bakar itu sendiri. Sekitar 62,3\% minyak bumi telah dimanfaatkan oleh seluruh kendaraan terutama kendaraan pribadi [2]. Adanya kelangkaan bahan bakar yang terus meningkat akhirnya mendorong para pakar untuk menemukan alternatif lain guna memenuhi kebutuhan bahan bakar untuk memenuhi kebutuhan sehari-hari masyarakat.

Salah satu cara untuk mengurangi penggunaan bahan bakar minyak adalah melakukan konversi terhadap tumbuhtumbuhan yang memiliki kandunagn selulosa menjadi suatu produk bioetanol. Bioetanol memiliki sifat etanol murni yang mudah terbakar dan memiliki nilai oktan yang tinggi yaitu 118 [3].

Pemanfaatan bioetanol sebagai pengganti bahan bakar minyak dapat membantu dalam mengurangi jumlah emisi karbon monoksida (CO), penurunan emisi Nitrogen Oksida (NOx) serta hidrokarbon dibandingkan dengan bahan bakar bensin biasa [4].

Penelitian mengenai pemanfaatan bioetanol sebagai bahan bakar sebelumnya telah dilakukan oleh Winanda dan Sudarmanta pada tahun 2017 dimana penelitiannya mengenai unjuk kerja dan durability mobil bensin 1497 cc menggunakan bahan bakar campuran bensin dan bioetanol 5,10,15\% melaporkan bahwa kenaikan tertinggi torsi rata-rata sebesar $4,2 \%$ pada E10, daya rata-rata tertinggi pada E10 dengan kenaikan 2,96\% dibanding bensin murni. Penurunan SFC
(Specific Fuel Consumption) tertinggi terjadi pada E10 sebesar 7,92\%. BMEP (Brake Mean Effective Pressure) tertinggi pada E10 sebesar 2,72\%. Emisi gas CO terendah didapatkan oleh E10 dan E15 dengan penurunan sebesar $15,30 \%$. Emisi gas $\mathrm{HC}$ terendah didapatkan oleh campuran E10 dengan penurunan sebesar $11.79 \%$ [5].

Berdasarkan penelitian sebelumnya dan potensi Provinsi Sumatera Selatan memiliki salah satu komoditas daerah berupa buah nanas akan menghasilkan limbah mahkota nanas yang cukup melimpah. Oleh karena itu, peneliti melakukan pengujian pengaruh variasi campuran bahan bakar pertamax dan bioetanol dari mahkota nanas terhadap emisi gas buang kendaraan bermotor 4 langkah. Motor yang diuji cobakan adalah sepeda motor merk Yamaha Fino tahun 2018.

Bahan bakar minyak utama yang digunakan dalam penelitian ini adalah bahan bakar pertamax. Pertamax merupakan bahan bakar baru yang sesuai dengan kebutuhan masyarakat di Indonesia dan banyak digunakan saat ini dengan nilai oktan 92 [3].

\section{Tinjauan Teoritis}

Bioetanol atau etanol $\left(\mathrm{C}_{2} \mathrm{H}_{5} \mathrm{OH}\right)$ merupakan salah satu alternatif bahan bakar terbarukan yang berasal dari tumbuhtumbuhan. Bioetanol dihasilkan dari biomassa yang memiliki kandungan glukosa dan dikonversi menjadi bahan bakar dengan melalui proses fermentasi memanfaatkan bakteri atau jamur. Produksi etanol dapat diperoleh baik dengan proses biologi maupun fisik [6].

Pengelompokkan biomassa sebagai bahan baku dalam pembuatan bioetanol terdiri atas [7]:

1) Sukrosa

Biomassa yang termasuk kedalam kelompok ini antara lain: nira, tebu, nira nipati, nira sargum manis, nira kelapa, nira aren dan sari buah mete.

2) Pati 
Biomassa yang termasuk kedalam kelompok ini adalah bahan- bahan yang mengandung pati. Bahan tersebut antara lain, umbi-umbian, jagung, sagu, bonggol pisang, ubi kayu, ubi jalar dan lain-lain.

3) Selulosa

Biomassa yang memiliki kandungan selulosa (lignoselulosa) merupakan bagian dari tumbuh-tumbuhan yang mengandung selulosa (serat), antara lain: kayu, jerami, alang-alang, daun kenaf, dan lain-lain.

Tabel 1. Sifat Fisik Bioetanol [8]

\begin{tabular}{|c|c|c|}
\hline No. & Sifat Fisik & Keterangan \\
\hline 1 & $\begin{array}{l}\text { Massa Molekul Relatif } \\
\text { (Mr) }\end{array}$ & $46,07 \mathrm{~g} / \mathrm{mol}$ \\
\hline 2 & Titik beku & $-114,1^{0} \mathrm{C}$ \\
\hline 3 & Titik didih normal & $78,32^{0} \mathrm{C}$ \\
\hline 4 & Densitas pada $20^{\circ} \mathrm{C}$ & $0,7893 \mathrm{~g} / \mathrm{ml}$ \\
\hline 5 & $\begin{array}{l}\text { Kelarutan dalam air } \\
20^{\circ} \mathrm{C}\end{array}$ & Sangat larut \\
\hline 6 & Viskositas $20^{\circ} \mathrm{C}$ & $1,17 \mathrm{cP}$ \\
\hline 7 & Kalor spesifik $20^{\circ} \mathrm{C}$ & $0,579 \mathrm{kal} / \mathrm{g}$ \\
\hline 8 & $\begin{array}{l}\text { Kalor pembakaran } \\
20^{\circ} \mathrm{C}\end{array}$ & $792,1 \mathrm{kal} / \mathrm{g}$ \\
\hline 9 & $\begin{array}{l}\text { Kalor penguapan } 78, \\
32^{\circ} \mathrm{C}\end{array}$ & $200,6 \mathrm{kal} / \mathrm{g}$ \\
\hline 10 & Rumus kimia & $\mathrm{C}_{2} \mathrm{H}_{5} \mathrm{OH}$ \\
\hline 11 & $\begin{array}{l}\text { Research Octane } \\
\text { Number }(\mathrm{RON})\end{array}$ & 111 \\
\hline 12 & Panas Laten & $725,4 \mathrm{~kJ} / \mathrm{L}$ \\
\hline
\end{tabular}

Bioetanol memiliki ciri-ciri berwarna bening, tidak memiliki nilai toksisitas yang tinggi, tidak terurai secara biologis dan memiliki emisi $\mathrm{CO}_{2}$ yang rendah saat terbakar sehingga tidak mencemari lingkungan. Kandungan oksigen dalam bioetanol dapat mengoksigenasi bahan bakar sehingga dapat terbakar secara sempurna [9].

Di Indonesia tanaman nanas sangat cocok untuk dibudidayakan karena sesuai dengan iklim di Indonesia. Salah satu sentra produksi nanas terbesar di Indonesia adalah Provinsi Sumatera Selatan. Pada umumnya masyarakat hanya memanfaatkan daging nanas saja sedangkan mahkota buah nanas tersebut biasanya langsung dibuang atau tidak digunakan lagi. Mahkota nanas ini dapat digunakan sebagai bahan baku pembuatan bioetanol karena memiliki kandungan selulosa. Selulosa dari mahkota nanas dikonversi menjadi glukosa dibantu oleh enzim selulase. Setelah glukosa terbentuk, tahapan selanjutnya glukosa akan difermentasi dengan bantuan mikroorganisme saccharomyces cereviseae [10].

Pada sepeda motor akan mengalami proses pembakaran antara bahan bakar dengan udara (oksigen), sedangkan nitrogen tidak ikut bereaksi. Oksigen adalah satu-satunya unsur di dalam udara yang dibutuhkan untuk membakar molekulmolekul bahan bakar [11].

Gas buang merupakan zat atau unsur dari pembakaran di dalam ruang bakar yang dilepas ke udara yang ditimbulkan oleh kendaraan bermotor. Gas buang hasil dari pembakaran atau uap bahan bakar ini terdiri atas beberapa senyawa, antara lain: CO (Carbon Monoxide), HC (Hydrocarbon) dan NOx (Nitrogen Oxide) (Ismiyati, Marlita, \& Saidah, 2014).

1. Hidrokarbon (HC)

Hidrokarbon adalah bahan bakar yang tidak terbakar selama proses pembakaran di dalam ruang bakar. emisi hidrokarbon berasal dari hasil samping proses pembakaran yang tidak sempurna, adanya karbon pada dinding ruang bakar dan minyak yang terdapat pada dinding ruang bakar. HC merupakan komponen bahan bakar yang tidak terbakar, dimana semakin tinggi emisi $\mathrm{HC}$ akan mengakibatkan berkurangnya tenaga mesin dan meningkatnya penggunaan bahan bakar.

2. Karbon Monoksida (CO)

Gas karbon monoksida (CO) dihasilkan pada saat motor beroperasi dengan perbandingan antara udara dan bahan bakar yang cukup melimpah.oleh karena itu, oksigen tidak mampu untuk mengkonversi seluruh karbon dari bahan bakar menjadi karbon dioksida $\left(\mathrm{CO}_{2}\right)$, sehingga ada komponen bahan bakar tidak terbakar dan membentuk terbentuk karbon monoksida (CO).

3. Nitrogen Oksida $\left(\mathrm{NO}_{\mathrm{X}}\right)$ 
Emisi gas buang berupa nitrogen oksida (NOx) dihasilkan dari proses pembakaran pada temperatur yang sangat tinggi. Udara yang digunakan untuk pembakaran memiliki kandungan Nitrogen sebesar $80 \%$. Dimana pada temperatur yang sangat tinggi, nitrogen akan menyatu dengan campuran bahan bakar sehingga terbentuklah senyawa $\mathrm{NO}_{x}$.

4. Karbon Dioksida $\left(\mathrm{CO}_{2}\right)$

Pada proses pembakaran, sangat diharapkan adanya karena jika semakin tinggi $\mathrm{CO}_{2}$ yang diperoleh maka semakin efisien operasi motor tersebut. Namun jika kadar $\mathrm{CO}_{2}$ kecil maka efisiensi pembakaran tidak bagus sehingga kinerja mesin juga tidak bagus. Akibatnya gas buang $\mathrm{CO}$ dan $\mathrm{HC}$ berlebih dan pemakaian bahan bakar yang boros.

\section{Metode Penelitian}

Alat dan bahan yang digunakan dalam penelitian ini antara lain : gelas ukur, exhaust gas analyzer AGS 688, pertamax dan bioetanol dari mahkota nanas.

Penelitian ini meliputi beberapa tahapan antara lain :

1. Pembuatan bioetanol dari mahkota nanas dengan metode sakarifikasi dan fermentasi serentak

Salah satu metode yang dilakukan untuk pembuatan bioetanol yaitu dengan proses simultaneous sacharificatian and fermentation (SSF) atau dikenal dengan proses sakarifikasi fermentasi serentak (SFS). Proses SSF yaitu kombinasi antara hidrolisis menggunakan enzim selulase dan ragi saccharomyces cerevisiae untuk fermentasi gula dari bahan baku mahkota nanas menjadi etanol secara bersamaan .

Tahap awal produksi bioetanol yaitu persiapan bahan baku mahkota nanas. Daun mahkota nanas dijemur hingga memiliki kelembaban maksimal $5 \%$. Mahkota nanas yang telah kering selanjutnya digiling hingga menjadi bubuk. Selanjutnya hasil gilingan mahkota nanas diayak dengan dengan ayakan 80-100 mesh.

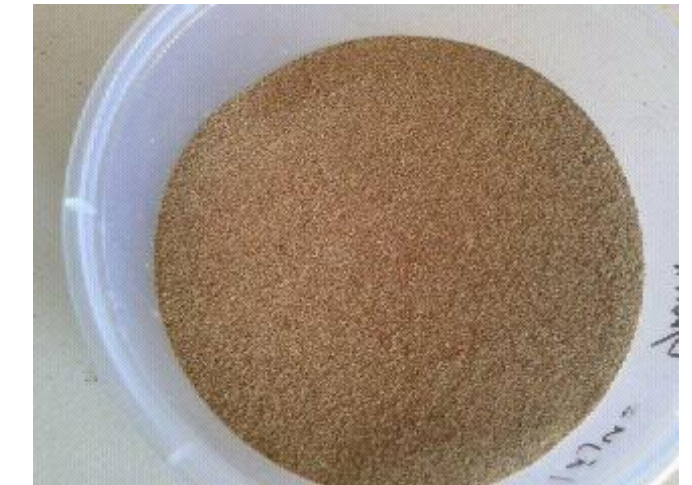

Gambar 2. Mahkota nanas ukuran 80-100 mesh

Bubuk mahkota nanas dicampurkan kedalam larutan nutrisi dengan perbandingan 1:2, kemudian disterilisasi selama 15 menit pada suhu $121^{\circ} \mathrm{C}$. Medium untuk SSF sebanyak $200 \mathrm{ml}$ dan nutrisi substrat atau medium antara lain $0,04 \mathrm{gr} / \mathrm{L}$ $\left(\mathrm{NH}_{4}\right)_{2} \mathrm{PO}_{4} ; 0,002 \mathrm{gr} / \mathrm{L} \mathrm{MgSO}_{4} .7 \mathrm{H}_{2} \mathrm{O}$ dan $0,08 \mathrm{gr} / \mathrm{L}$ yeast extract.

Tahap selanjutnya yaitu persiapan yeast inokulum. Pembuatan yeast inokulum bertujuan untuk mengadaptasikan sel yeast terhadap media fermentasi. Dengan adanya adaptasi diharapkan fase lambat sebagai tahap awal fermentasi terlewati. Saccharomyces cerevisiae diinokulasi dalam $150 \mathrm{ml}$ medium (5 gr glukosa; 0,5 gr yeast extract; 0,05 gr $\mathrm{KH}_{2} \mathrm{PO}_{4} ; 0,05 \mathrm{gr}$ $\mathrm{MgSO}_{4.7} \mathrm{H}_{2} \mathrm{O}$ dan 0,05 gr $\left(\mathrm{NH}_{4}\right) 2 \mathrm{SO}_{4}$, aquades) dalam erlenmeyer $250 \mathrm{ml}$. Sebelum diinokulasi, mediadisterilisasi uap dalam autoclave selama 15 menit pada temperatur $121^{\circ} \mathrm{C}$, kemudian didinginkan. Setelah dingin ragi dimasukan ke dalam media lalu diaduk menggunakan shaker selama 24 jam. Fungsi shaker adalah mempermudah difusi oksigen ke dalam medium dan campuran menjadi homogen. Tahap selanjutnya yaitu proses pembuatan bioetanol dengan metode simultaneous sacharificatian and fermentation (SSF).

Proses SSF dilakukan dengan cara menambahkan sejumlah inokulum ragi saccharomyces cereviseae dan enzim selulase ke dalam medium fermentasi dengan komposisi 14\%. Selanjutnya fermentasi dilakukan pada suhu kamar selama 96. Hasil dari fermentasi kemudian dievaporasi atau diuapkan untuk 
memisahkan bioetanol dari komponen lainnya sesuai dengan titik didih etanol yaitu pada suhu $70^{\circ} \mathrm{C}$ [10].

2. Pencampuran pertamax dan bioetanol

Pada tahapan ini, dilakukan pencampuran antara bahan bakar pertamax dan bioetanol yang telah didapatkan dengan cara mengukur volume campuran bahan bakar pertamax dan bioetanol yang digunakan menggunakan gelas ukur. Untuk komposisi volume bahan bakar dapat dilihat pada Tabel 2.

Bahan bakar pertamax dan bioetanol yang telah diukur volumenya dimasukkan ke dalam botol, yang selanjutnya dilakukan proses pengadukan agar bahan bakar pertamax dan bioetanol tercampur secara merata. Kemudian campuran bahan bakar pertamax dan bioetanol tersebut disimpan selama satu malam sebelum digunakan, proses ini dilakukan agar bahan bakar pertamax dan bioetanol lebih tercampur lagi. Persentase campuran pertamax dan bioetanol dapat dilihat pada Tabel 2 .

Tabel 2. Komposisi Campuran Pertamax dan Bioetanol tiap 1 liter

\begin{tabular}{lcc}
\hline \multicolumn{1}{c}{ Variasi } & Pertamax & Bioetanol \\
\hline $\mathrm{E}_{0}($ Pertamax $)$ & $1000 \mathrm{ml}$ & $0 \mathrm{ml}$ \\
$\mathrm{E}_{5}($ Bioetanol 5\%) & $950 \mathrm{ml}$ & $50 \mathrm{ml}$ \\
$\mathrm{E}_{10}($ Bioetanol 10\%) & $900 \mathrm{ml}$ & $100 \mathrm{ml}$ \\
$\mathrm{E}_{15}($ Bioetanol 15\%) & $850 \mathrm{ml}$ & $150 \mathrm{ml}$ \\
$\mathrm{E}_{20}($ Bioetanol 20\%) & $800 \mathrm{ml}$ & $200 \mathrm{ml}$ \\
\hline
\end{tabular}

\section{Prosedur pengujian}

Adapun prosedur pengujian dalam penelitian ini adalah sebagai berikut :

1) Mengisi tangki bahan bakar dengan bahan bakar yang ingin digunakan, dengan terlebih dahulu mengosongkan sisa bahan bakar pada tangki dan selang bahan bakar, bahan bakar yang digunakan yaitu $\mathrm{E}_{0}, \mathrm{E}_{5}, \mathrm{E}_{10}, \mathrm{E}_{15}$ dan $\mathrm{E}_{20}$.

2) Memperhatikan dan memastikan tidak ada udara yang terjebak di dalam saluran selang bahan bakar

3) Memanaskan mesin kurang lebih selama 5 menit agar mesin dalam kondisi siap kerja.
4) Menghubungkan Exhaust Gas Analyzer AGS 688 ke arus listrik.

5) Menghidupkan tombol Exhaust Gas Analyzer AGS 688 yang berada dibelakang alat.

6) Memilih menu gas analysys pada menu Exhaust Gas Analyzer AGS 688

7) Memilih menu measurement pada menu Exhaust Gas Analyzer AGS 688.

8) Memilih menu standar test pada menu Exhaust Gas Analyzer AGS 688. Selanjutnya unit stargas 898 secara otomatis melakukan warming up kurang lebih selama 60 detik, kemudian melakukan auto zero secara otomatis yang berfungsi untuk mereset data dari awal.

9) Menghidupkan mesin dan mengatur putaran mesin pada $2500 \mathrm{rpm}$ dengan beban dinamometer pada bukaan katup 0,5 .

10) Memasukkan probe sensor kedalam kenalpot.

11) Menunggu sampai angka dilayar exhaust gas analyzer AGS 688 sampai stabil.

12) Mencetak hasil pengujian pada exhaust gas analyzer AGS 688 .

13) Melakukan pengujian dengan variasi bahan bakar yaitu pertalite dan campuran bahan bakar pertalite dan bioetanol 0\%, 5\%, 10\%, 15\%, dan 20\% dengan pengulangan pengujian sebanyak 3 kali.

\section{Hasil dan Pembahasan}

Berdasarkan hasil penelitian uji emisi yang dilakukan di Laboratorium Dinas Lingkungan Hidup Kota Palembang menggunakan mesin sepeda motor empat tak satu silinder merk Yamaha Fino Tahun 2018. Parameter yang diteliti adalah data emisi pada setiap variasi bahan bakar.

Bahan bakar yang digunakan antara lain bahan bakar pertamax murni (E0), campuran bioetanol 5\% dan pertamax $95 \%$ (E5), campuran bioetanol $10 \%$ dan pertamax 90\% (E10), campuran bioetanol $15 \%$ dan pertamax $85 \%$ (E15), dan 
campuran bioetanol $20 \%$ dan pertamax $80 \%$ (E20).

Tabel 3. Hasil pengujian kandungan emisi bahan bakar

\begin{tabular}{llllll}
\hline & \multicolumn{5}{c}{ Campuran bioetanol dan pertamax } \\
Exhaust gas & $\mathrm{E}_{0}$ & $\mathrm{E}_{5}$ & $\mathrm{E}_{10}$ & $\mathrm{E}_{15}$ & $\mathrm{E}_{20}$ \\
\hline $\mathrm{CO}(\%)$ & 3,20 & 2,68 & 2,06 & 1,46 & 1,33 \\
$\mathrm{CO}_{2}(\%)$ & 5,91 & 6,82 & 6,96 & 7,06 & 7,22 \\
$\mathrm{HC}(\mathrm{ppm})$ & 167,5 & 138 & 75 & 82 & 90,5 \\
\hline
\end{tabular}

Berdasarkan data Tabel 3 maka dapat diintegrasikan dalam bentuk grafik seperti ditunjukkan pada Gambar 1.

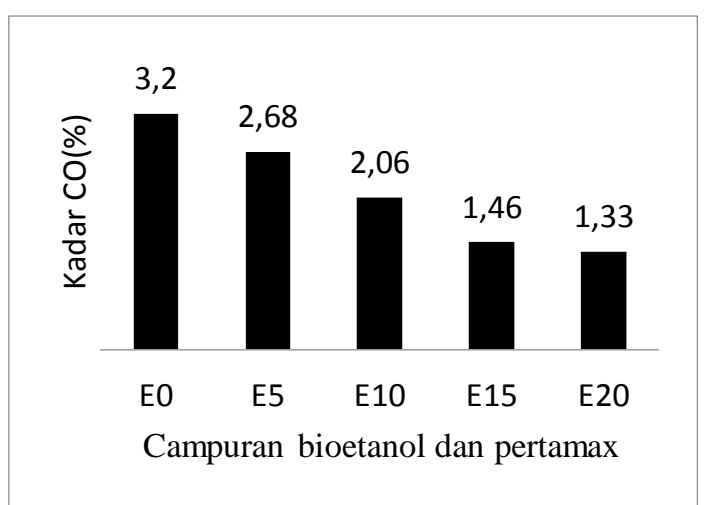

Gambar 1. Pengaruh Penambahan bioetanol terhadap kadar $\mathrm{CO}(\%)$

Penggunaan bahan bakar E0 menghasilkan kadar CO sebesar 3,20 \%vol. Bahan bakar E5 mengalami penurunan menjadi 2,68 \%vol. Bahan bakar E10 menghasilkan kadar $\mathrm{CO}$ lebih kecil yaitu 2,06 \% vol. Penggunaan E15 menghasilkan CO lebih kecil dari E10 yaitu sebesar 1,46 \%vol dan bahan bakar E20 menghasilkan CO lebih kecil dari E15 yaitu sebesar 1,33 $\%$ vol.

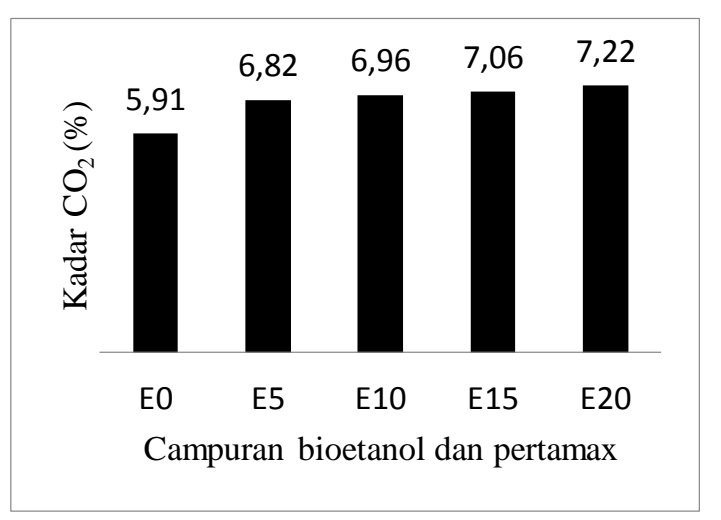

Gambar 2. Pengaruh Penambahan bioetanol terhadap kadar $\mathrm{CO}_{2}(\%)$
Sedangkan pada penggunaan bahan bakar E0 menghasilkan kadar $\mathrm{CO}_{2}$ sebesar 5,91 \%vol. Bahan bakar E5 mengalami peningkatan menjadi $6,82 \%$ vol. Bahan bakar E10 menghasilkan kadar $\mathrm{CO}_{2}$ lebih besar yaitu 6,96 \%vol. Penggunaan E15 menghasilkan $\mathrm{CO}_{2}$ lebih besar dari E10 yaitu sebesar 7,06 \%vol dan bahan bakar E20 menghasilkan $\mathrm{CO}_{2}$ lebih besar dari E15 yaitu sebesar 7,22 \%vol.

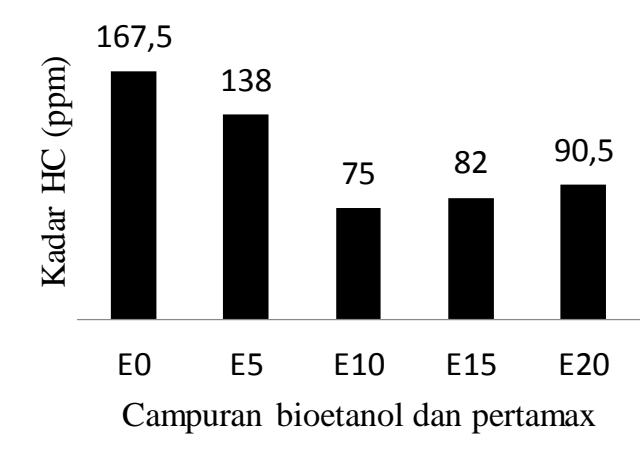

Gambar 3. Pengaruh Penambahan bioetanol terhadap kadar HC (ppm)

Pengujian emisi gas buang pada motor dilakukan pada saat kondisi mesin idle. Dari hasil uji menunjukkan penggunaan bioetanol memberi efek positif terhadap lingkungan. Semakin tinggi persentase etanol maka tingkat penurunan emisi semakin bagus.

Dari beberapa pengujian emisi gas buang diatas maka nilai yang memiliki kisaran gas beracun yang paling minimal yaitua pada bahan bakar E10. Maka dapat dikatakan bahan bakar biopertamax E10 memenuhi Peraturan Menteri Lingkungan Hidup No. 05 tahun 2006. yaitu untuk konsentrasi CO sebesar $5.5 \%$ vol dan HC sebesar $2400 \mathrm{ppm}$ pada putaran idle untuk sepeda motor 4 langkah.

\section{Kesimpulan}

Berdasarkan hasil penelitian yang telah dilakukan maka dapat diambil kesimpulan bahwa pencampuran pertamax dengan bioetanol dapat menurunkan nilai emisi gas buang dari gas buang knalpot kendaraan bermotor. Penurunan emisi gas buang HC yang terbesar yaitu pada 
penggunaan bahan bakar Eo dihasilkan penurunan emisi gas buang HC sebesar 135 ppm pada E5 dan disusul oleh bahan bakar E10 dengan besar penurunan emisi HC yaitu sebesar 75 ppm tetapi pada bahan bakar E15 mengalami peningkatan kembali sebesar $82 \mathrm{ppm}$ dan disusul pada bahan bakar E20 sebesar 90,5 ppm. Pada emisi gas buang $\mathrm{CO}$ didapatkan nilai kadar $\mathrm{CO}$ terkecil yaitu dihasilkan oleh penggunaan bahan bakar E20 sebesar 1,33 \%. Terjadinya penurunan kadar $\mathrm{CO}$ seiring dengan meningkatnya jumlah bioetanol yang ditambahkan kedalam pertamax.

\section{Ucapan Terimakasih}

Tim peneliti mengucapkan terima kasih kepada Yayasan Pendidikan Tinggi Nasional Tridinanti yang telah mendanai penelitian ini pada tahun anggaran 2019 dengan Surat Perjanjian Nomor : 092/UTP.A12/LPPM/V/2019 Tanggal:18 05-2019.

\section{Referensi}

[1] Rahardjo Tirtoatmodjo, et al., 2000. Peningkatan Unjuk Kerja Motor Bensin Empat Langkah Dengan Penggunaan Busi Dua Elektrode Dan Busi Tiga Elektrode. Jurnal Teknik Mesin.

[2] Afan Agrariksa, F., et al., 2013. Uji Performansi Motor bakar Bensin (On Chassis) Menggunakan Campuran Premium dan Etanol Performance Test of Gasoline Engine (On Chassis) by Use Mixed Premium and Ethanol. Jurnal Keteknikan Pertanian Tropis Dan Biosistem, 1(3), 194-203.

[3] Winarno, J. 2011. Studi Eksperimental Pengaruh Penambahan Bioetanol Pada Bahan Bakar Pertamax Terhadap Unjuk Kerja Motor Bensin. Jurnal Teknik, 1(1), 33-39.

[4] Dharmawan, D., \& Sudarmanta, B. 2015. Studi Eksperimen Pengaruh Rasio Kompresi dan Durasi Penginjeksian Bahan Bakar Terhadap Unjuk Kerja dan Emisi Gas Buang
Engine Honda CB150R Berbahan Bakar Bioetanol E100. (October 2016).

[5] Winanda, P. H., \& Sudarmanta, B. 2016. Uji Unjuk Kerja dan Durability 5000 Km Mobil. Jurnal Teknik ITS, 5(2), 678-683.

[6] Jeuland, N., et al., 2004. Potentiality of Ethanol As a Fuel for Dedicated Engine. Oil \& Gas Science and Technology.

https://doi.org/10.2516/ogst:2004040

[7] Nasrun, et al., 2015. Pengaruh Jumlah Ragi dan Waktu Fermentasi terhadap KadarBioetanol yang Dihasilkan dari Fermentasi Kulit Pepaya. Jurnal Teknologi Kimia Unimal.

[8] Rahmawati. 2010. Pemanfaatan Limbah Kulit Ubi Kayu (Manihot Utilissima Pohl.) Dan Kulit Nanas (Ananas Comosus L.) Pada Produksi Bioetanol Menggunakan Aspergillus Niger. In Universitas 11 Maret.

[9] Sastrohamidjojo, H., \& Fariyatun, E. 2016. Synthesis of Methyl Eugenol from Crude Cloves Leaf Oil Using Acid and Based Chemicals Reactions. IOSR Journal of Applied Chemistry (IOSR-JAC. https://doi.org/10.9790/5736091002105112

[10] Suci Rahmadani, et al., 2017. Produksi Bioetanol Dari Mahkota Nanas Menggunakan Bakteri Zymomonas Mobilis Dengan Variasi Konsentrasi Inokulum Dan Penambahan Nutrisi Suci. Fteknik, 38(4), 1639-1642. https://doi.org/10.16362/j.cnki.cn611023/h.2017.03.016

[11]Mahidin, et al.,2017. Karakteristik Pembakaran Beberapa Jenis Biomassa dalam Fluidized Bed Boiler. Jurnal Rekayasa Kimia \& Lingkungan. https://doi.org/10.23955/rkl.v10i1.2167

[12] Ismiyati, et al., 2014. Pencemaran Udara Akibat Emisi Gas Buang Kendaraan Bermotor. Jurnal Manajemen Transportasi \& Logistik (JMTransLog). 